\title{
Determinants of sex differentials in mortality: an assessment of household- level factors in South Africa
}

\author{
Pierre Dindi \& Nicole De Wet \\ Demography and Population Studies, Schools of Social Sciences and Public Health, \\ University of the Witwatersrand, Johannesburg, \\ South Africa, \\ Email: p.dindi@gmail.com
}

\begin{abstract}
Background: Increasingly high male mortality hinders progress towards improving overall life expectancy.

Data Source \& Method: The study used data from South Africa's 2016 Community Survey to examine the household-level determinants of male mortality. Chi square tests and binary logistic regression were used.

Results: Out of the 30,022 deaths in the sample, males comprised $52.8 \%$. Male deaths were high at all ages except for age group 75+ years. Odds of male mortality were higher (OR:2.08; Cl:I.98-2.18) among those that lived in female headed households or White-headed households (OR:I.50;Cl:I.29I.73). There was less likelihood of male deaths (OR:0.9l;Cl:0.87-0.97) in households that were not involved in agriculture.

Conclusion: Overall, mortality differentials were largely explained by household demographics including age, race and gender dynamics of heads of households. We recommend a multi-sectoral policy and programme implementation that promotes deliberate inclusiveness of household characteristics in their delivery.
\end{abstract}

Keywords: South Africa, mortality, longevity, logistic regression, households

\section{Introduction}

South Africa has experienced a substantial decline in mortality from all causes since the mid-2000s (Pillayvan Wyk et al., 2016). In the years that preceded, the death toll had increased from 416,209 in 1997 to its highest peak in $2006(677,078)$ before declining to 528,946 in 2012 and 456,6I2 in 2016 (Pillay-van Wyk et al., 2016; Statistics South Africa, 2018). This decline has been accompanied by increases in longevity over this period. According to the mid-year population estimates for 2014, the total life expectancy at birth had increased from 53 years in 2006 to 6I.2 years (Statistics South Africa, 20/4). Currently, an average person in South Africa is expected to live up to 64 years (Statistics South Africa, 2017a).

The decline in mortality has mainly been attributed to the onset of the Anti-Retroviral Treatment (ART) programme in 2004, which saw AIDS-related deaths recede from $34 \%$ to $21 \%$ between 2006 and 2014 (Bor et al., 2013; Johnson et al., 20I7; Statistics South Africa, 2018). The declining burden of infectious diseases also explains the reduction in mortality: it is only about a decade ago when tuberculosis, intestinal infections and pneumonia accounted for $12 \%, 8.7 \%$ and $6.5 \%$ deaths in the country respectively (Statistics South 4631
Africa, 2008). Today, tuberculosis, though still the leading cause of mortality in South Africa, only accounts for $6.5 \%$ of deaths, whereas intestinal infections and influenza-attributable deaths reduced to $3.1 \%$ and $4.5 \%$ respectively (Statistics South Africa, 20|8).

Of notable mention is the increase in the level of non-communicable diseases and their associated mortality. Between 1997 and 2009, cardiovascular diseases were the highest cause of death in South Africa (Udjo \& Lalthapersad-Pillay, 20I4). In 2008, $42 \%$ of adults had high blood pressure. More than half of them were physically inactive, whereas 65\% were overweight and obese (Nojilana et al., 20I6b). By 2010, mortality estimates in South Africa indicated that $39 \%$ of deaths were ascribed to noncommunicable diseases, with one-third of them occurring before the age of 60 years (Nojilana et al., 2016a). A comparison between the 2006 and 2010 levels of non-communicable diseases shows an overall increase in their prevalence (Statistics South Africa, 2008, 2018). This has been attributed to improved diagnosis coupled with unmet need for treatment among patients with non-communicable diseases, especially in the public sector (Folb et al., 2015). While it is projected that these emerging 
diseases will be the major cause of mortality by 2030 , their current levels are not high enough to offset the declining trends of deaths resulting from receding infections (Alwan, 20l I).

So far, the reduction and containment of morbidity have set the country on course to further declines in mortality. However, there has been a steady increase in sex differentials in mortality over the past decade. Among the deaths that occurred in 2006, females accounted for $49.3 \%$ while $50.7 \%$ of them were in males. By 2016, the share of males dying had increased to $52.7 \%$ thus, widening the mortality gap from I.4\% to $5.3 \%$ between the sexes (Statistics South Africa, 2018, 2008). While there were 103 male deaths for every 100 female deaths in 2006, overtime, the ratio soared to 112 male deaths by the year 2016 (Statistics South Africa, 2018). A similar pattern with more conspicuous differences can be observed with life expectancies at birth. At the onset of the mortality decline in 2006, females only lived 2.4 years longer than males. Currently, females in South Africa outlive males by 5.5 years (Statistics South Africa, 2018).

One of the population targets for the National Development Plan (NDS) for the Republic of South Africa is to reach a total life expectancy of 70 years by the year 2030 (National Planning Commission, 201 I). In 2016, South Africa experienced an unprecedentedly wide gap in male versus female mortality since the year 2000 as evidenced by the sex ratios at death (Statistics South Africa, 2018). Thus, efforts to narrow the sex-gap in mortality patterns are likely to go a long way at raising overall longevity in the population, a phenomenon that increases the returns on human capital investments (Cervellati and Sunde, 2005).

A number of studies on the correlates of mortality in South Africa have focused on individual behavioural and biological risk factors than at the household level (Clark et al., 2007; Cornell et al., 20I2; Kahn et al., 2007). Furthermore, Beltrán-Sánchez et al., (2015) argue that the sex differences in mortality only dates as far back as just over a hundred years ago having analysed more than 1700 cohorts born in the 19th century. Thus, the fact that females outlive males needs not be normalised considering its possible effect on inhibiting faster increase in total life expectancy.

In order to answer the question in this study, this paper analyses the household demographic, household socio-economic and household environmental factors of mortality in order to determine the sex differences in deaths. With this objective in mind, it is expected that the findings of this paper will help inform strategies and programmes on mitigating the risk factors of mortality.

\section{Empirical analysis of adult mortality}

Adult mortality in Sub-Saharan Africa has been explained by a myriad of determinants. Pertinent among them is the framework for analysing adult mortality developed by Rogers et al. (2005). The framework illustrates the interplays among demographic factors (e.g. age, sex and race), distal causes (e.g. socio-economic status and environmental hazards) and proximate determinants of adult mortality (e.g. individual health behaviours and health status). This is informed by the rationale that the probability of dying varies with age, sex, race, socioeconomic and health status, among other risk factors (Rogers et al., 2005).

The framework suggests that mortality is a direct outcome of proximate determinants such as health behaviours, health states and physiology, which come about as a result of distal causes. As such, these distal determinants (such as geographical factors, social relations and social economic status) are perceived as indirectly influencing mortality. It is these factors that also mediate the influence of demographic characteristics (such as age, sex and race) and proximate mortality determinants (Rogers et al., 2005).

In 2012, the number of deaths resulting from all causes in South Africa was reported to be very high among children below the age of one. The numbers reached their peak during ages 35-39 years before slightly declining and maintaining their levels through to older age groups (Pillay-van Wyk et al., 2016). On the other hand, the rate of mortality experience at different ages showed a different pattern altogether. Figure I shows lower death rates per 1000 population for both males and females. Gendered differences however become visible during teenage years as the gap in mortality rates increasingly widens (Statistics South Africa, 2018, 2016a). Thus, with an exception of age group 0-4 years, sex differentials in mortality increase with age. Although the overall mortality is evidently declining, studies like Tomlinson, (2017) have argued that South Africa's mortality levels are still high given the level of the country's economy.

Race and ethnicity have also been noted to affect morbidity and mortality in both children and adults in South Africa. The most recent National Burden of Disease study in the country shows that most Black Africans die from HIV/AIDs and tuberculosis, whereas the major cause of death among Coloureds, Whites and Indians were non-communicable diseases (Pillay-van Wyk et al., 20I6). While HIV/AIDS and tuberculosis were the second leading cause of death 
among Coloureds and Indians, the former group experienced more deaths from it (Pillay-van Wyk et al., 20l6).

Meanwhile, a study by Heaton and Amoateng (2007) delved more into the racial dynamics of mortality within the first sixty months of life. A Kaplan-Meier survival plot showed higher child survival among Whites, followed by Indians, whereas the probability of dying was higher among Black African children with just over a 0.6 probability of surviving to age five. With regards to chronic and latent infections, two separate studies on breast and prostate cancer in South Africa equally found comparable racial patterns in their occurrence (Babb et al., 20l4; Singh et al., 2016). Within Sub-Saharan Africa, ethnic groups in Northern Nigeria have reported higher child mortality risks. These have been associated household environmental risks factors of the mother (Olufunke \& Obafemi, 20I I).

Figure I: Age specific mortality rates for males and females in South Africa, 2016

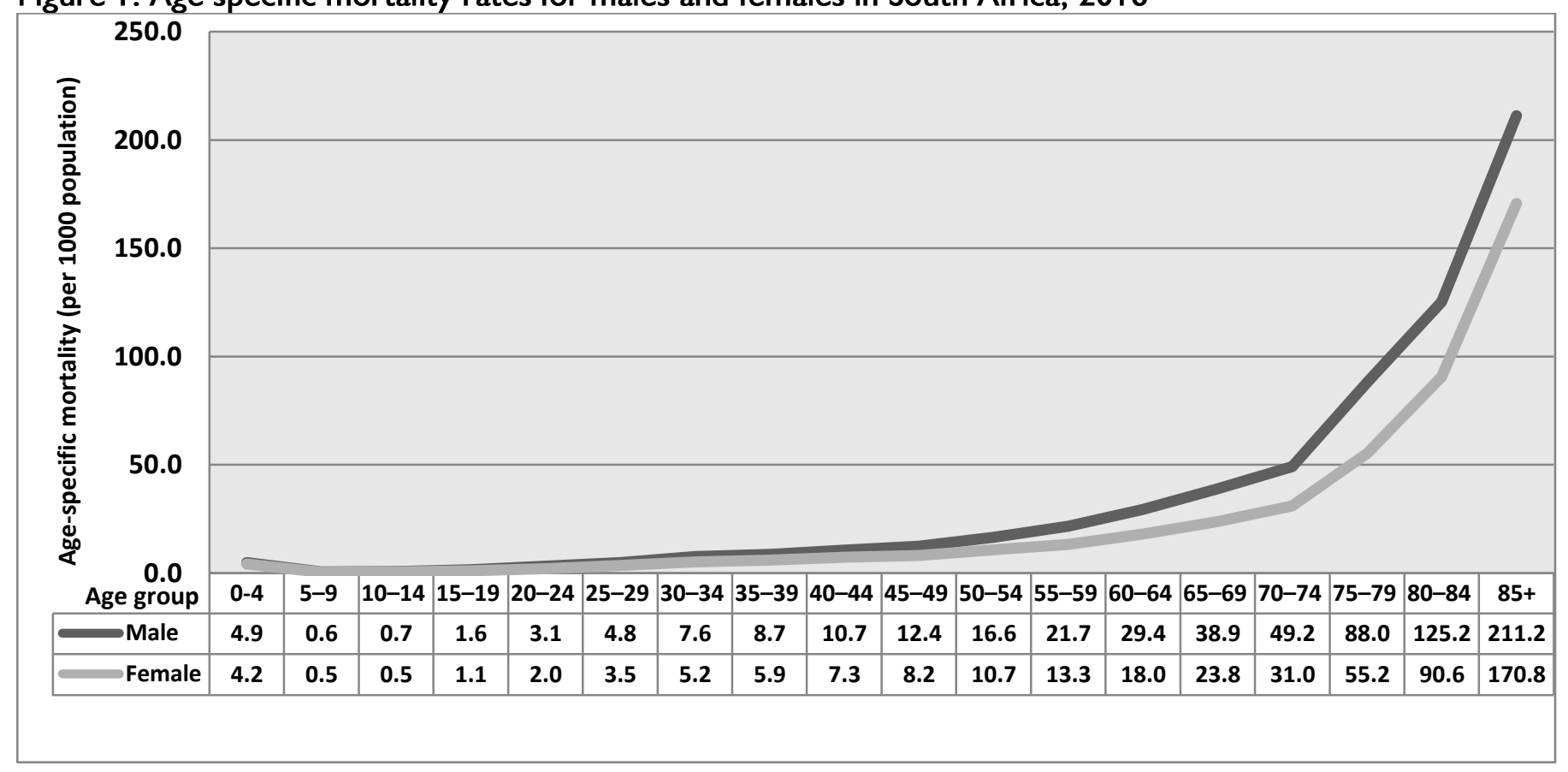

Source: Graph generated by authors based on the 2016 Community Survey (Statistics South Africa, 2016), and the Mortality and Causes of Death findings for 2016 (Statistics South Africa, 2018)

Of notable mention is the mortality distribution driven by population sex structure, which happens to be the key theme in this paper. Different schools of thoughts have shown that mortality in South Africa is strongly gendered, with overall figures being higher among males (Cornell et al., 2017; Nathan, 2012; Pongou, 2013; Wira and Fahey, 2008). Surprisingly, the top ten causes of mortality in the country explain $70 \%$ of deaths in females, but $67 \%$ in males (Pillayvan Wyk et al., 2016). This may imply that the excess male mortality is attributable to causes other than the ten main leading ones.

\section{Distal (intermediate factors)}

Positive correlations between level of education and mortality can be observed in the findings from a retrospective study of young people between 2009 and $20 \mathrm{II}$. The results indicate that progression to secondary school among youths aged 15-24 increased their overall AIDS-related death rates and probability of dying (De Wet, 20I6). This finding can, however, not be generalised as its analysis was on 4633 cause-specific mortality (HIV). Otherwise, it is a wellestablished phenomenon that low levels of education are associated with higher risks of mortality (Chisumpa et al., 2017; Hunter et al., 2007; Krueger et al., 2015). A similar pattern was exhibited between mortality and socio-economic status. For instance, populations with low income levels have reported higher cases of under-five morbidity and mortality compared to high income earners (Zere and Mclntyre, 2003). Such findings are in concordant with each other considering that higher educational attainment is a precursor for increased income levels.

At household level, spousal abuse among married females was found to increase the likelihood of maternal and neonatal deaths in South Africa (MmusiPhetoe, 2016). This alone implies a higher risk of exposure to mortality determinants among married females. This finding contests that from the Agincourt Demographic Surveillance Area (ADSA) which showed the probability of dying to be higher among divorced/separated and widowed females (Shoko, $20 \mathrm{II}$ ). On the other hand, loss of a parent has effects http://aps.journals.ac.za 
on the survival of the remaining children at the household (Sartorius et al., 201 I). However, this protective factor of parental presence is more pronounced among first born male children than later born children (Dong et al., 2017). South African households are characterised by a considerable prevalence of multigenerational compositions of at least three co-resident generations (International Longevity Centre, 20I2). On that note, Dong et al. (2017) argue that the effect of parental absence on male child mortality still by far outweighs that of a coresident kin.

\section{Data and methods}

\section{Source of data}

Data for this study was obtained from the Community Survey for 2016 (Statistics South Africa, 2016a). This is the second largest survey in South Africa that collects information at national, provincial and municipal levels on population, health, water and sanitation, housing and transportation. Dwelling units were identified using a stratified single stage sample design. Details on the survey sampling methodology are outlined in the technical report (Statistics South Africa, 2016b). The 2016 Community Survey employed a questionnaire that was developed using the World Bank's Survey Solutions online application. A total of 1,370,809 interviews were conducted to collect information in the following major categories: personal level data, housing, household and agricultural activities, emigration data and mortality. Thus, information on deaths was collected via proxies at household level. As such, the analysis in this paper used data from both the mortality and household files.

The dataset included 986,383 observations surveyed from across all nine provinces between 2015 and 2016. Deaths were reported in 30,058 of them, out of which 15,840 were males and 14,182 were females. Thirty-six observations were excluded because their sex was unspecified, thus leaving a sample of 30,022 for analysis.

\section{Description of variables}

In order to determine the outcome variable of this study (sex of the deceased), the respondent was asked if any death had occurred in the household in a period of 12 months before the interview date. For those that responded yes, a follow up question was asked on whether the deceased was/were male or female. Independent variables were identified based on both the framework for analysing adult mortality (Rogers et al., 2005), and their reported influence from literature. The framework was adapted to befit the household focus of the study. As such, variables age at death, age of the household head, sex of the household head, race of the household head, province and place of residence were classified as household demographics. The second variable category was classified as household socio-economic factors comprising variables: type of dwelling for the deceased, source of household drinking water, access to electricity, source of energy for cooking, household involvement in agriculture and type of toilet used. The last category included household environmental factors: whether a toilet was shared with neighbouring households, experience of crime by a household member and type of rubbish disposal used by household.

\section{Methods}

In order to conduct the analysis, descriptive statistics were performed through frequency tables to inspect the distributions of the variables. Cross tabulations were performed to examine the relationships between independent variables and sex of the deceased. For categorical variables, the chi-square test of independence was performed at a significance level of $\alpha<0.05$. Finally, since the outcome variable was dichotomous, logistic regression models were fit in order to examine the influence of household covariates in predicting sex of the deceased. In order to run inferential statistics, reported sex was recoded as 0 if the deceased was female and $I$ if they were male. The age variables were regrouped into 15 -year age groups from $0-14$ (as the youngest age group) to $75+$ (as the oldest age group), as opposed to the conventional I5-year groups. This was done in order to minimize the number of categories for these variables, as the age ranges were wide.

\section{Study limitations}

While age at death was determined in retrospect by enquiring from respondents whose households had experienced at least one death in the past year, data on age of the household head was more aligned with the timing of the survey. As such, caution needs to be exercised when interpreting these results, as heads of households may have been slightly younger at the time of death of the household member. Another limitation is that much as the study analysed demographic and distal determinants of adult mortality, data on proximate determinants could not be included. Had such data been available in the dataset, the study could have provided richer evidence about the influence of health behaviours, health conditions and human physiology on mortality outcomes. Lastly, the cross sectional nature of the study design made it challenging to establish causality between determinants and mortality outcomes, but rather associations. Nevertheless, we believe the results of this study will shed more light on the 
drivers of premature male mortality in South Africa and create a basis for stronger designs like cohort studies.

\section{Results}

Characteristics of the deceased

Between 2015 and 2016, over 30,000 deaths were reported in the sample out of which, $52.8 \%$ were males and $46.2 \%$ were females. These proportions are similar to the 2016 findings from death notifications by (Statistics South Africa, 2018). Table I provides the distribution of the differences in mortality across a selected number of factors.

\section{Distribution of mortality}

A closer look at the findings in table I shows higher proportions of male deaths for almost every age group. Among the oldest populations, however, a drastic inverse of this happens. Deaths that occurred among populations older than 74 years, compared to other age groups, were relatively higher among females (2I.4\%) than males (12\%). Nevertheless, a different pattern is noted when one considers mortality occurrence by age of the household head. Among the youngest heads of households (aged below 15 years), male mortality was proportionally lower in comparison to female mortality. Additionally, having a household head aged between I5 and 29 was most protective of male survival, as their deaths only comprised $10.7 \%$ compared to $15.2 \%$ among females. Further gains in male survival were noted if the head of the house was a fellow male. Out of all male deaths that occurred, only $30.9 \%$ were in male-headed households. This further shows a higher prevalence of mortality among males who resided in female-headed households. Differences in proportions by deaths were marginal when observed in terms of the race of the head of household. There were slightly more male deaths (3.2\%) than female deaths $(2.6 \%)$ in households that were headed by a White person.

Table I: Covariates of mortality within sexes in South Africa between 2015 and 2016

\begin{tabular}{|c|c|c|c|c|}
\hline & Sex of Dece & $\operatorname{ased}(n) \%$ & (n) $\%$ & \\
\hline & Female & Male & Total & \\
\hline Age at death (years) & & & & $x^{2}=489.2 ; p=0.00$ \\
\hline $0-14$ & (I,395) 9.8\% & $(1,734) 10.9 \%$ & $(3,129) 10.4 \%$ & \\
\hline $15-29$ & (I,387) $9.8 \%$ & (I,806) II.4\% & $(3,193) 10.6 \%$ & \\
\hline $30-44$ & $(2,794) 19.7 \%$ & $(3,408) 21.5 \%$ & $(6,202) 20.6 \%$ & \\
\hline $45-59$ & $(2,687) 18.9 \%$ & $(3,530) 22.2 \%$ & $(6,217) 20.7 \%$ & \\
\hline $60-74$ & $(2,797) 19.7 \%$ & $(3,344) 21.1 \%$ & $(6, \mid 4 I) 20.4 \%$ & \\
\hline $75+$ & $(3,042) 21.4 \%$ & (I,909) $12.0 \%$ & $(4,95 I) 16.4 \%$ & \\
\hline Age of household head (years) & & & & $x^{2}=248.7 ; p=0.00$ \\
\hline $0-14$ & (I3) $0.1 \%$ & (I0) $0.1 \%$ & (23) $0.1 \%$ & \\
\hline $15-29$ & $(2,167) \mid 5.2 \%$ & (I,696) $10.7 \%$ & $(3,863) \mid 2.8 \%$ & \\
\hline $30-44$ & $(3,725) 26.2 \%$ & (3,643) $23.0 \%$ & $(7,368) 24.5 \%$ & \\
\hline $45-59$ & $(4,080) 28.7 \%$ & $(4,833) 30.5 \%$ & $(8,913) 29.6 \%$ & \\
\hline $60-74$ & (2,984) $21.0 \%$ & $(4,064) 25.6 \%$ & $(7,048) 23.4 \%$ & \\
\hline $75+$ & $(1,213) 8.5 \%$ & (I,594) $10.0 \%$ & $(2,807) 9.3 \%$ & \\
\hline Sex of household head & & & & $x^{2}=979.2 ; p=0.00$ \\
\hline Male & $(6,879) 48.5 \%$ & $(4,886) 30.9 \%$ & $(11,765) 39.2 \%$ & \\
\hline Female & $(7,303) 51.5 \%$ & $10,954) 69.2 \%$ & $(18,257) 60.8 \%$ & \\
\hline Race of household head & & & & $x^{2}=10.9 ; p=0.01$ \\
\hline Black African & (I2,790) $90.2 \%$ & $(\mid 4,138) 89.3 \%$ & $(26,928) 89.7 \%$ & \\
\hline Coloured & (90I) $6.4 \%$ & $(1,057) 6.7 \%$ & $(1,958) 6.5 \%$ & \\
\hline Indian/Asian & (I25) $0.9 \%$ & (I43) $0.9 \%$ & (268) $0.9 \%$ & \\
\hline White & (366) $2.6 \%$ & 302 (502) & (868) $2.9 \%$ & \\
\hline Type of dwelling for the decease & & & & $x^{2}=10.1 ; p=0.6$ \\
\hline Formal dwelling/house & $(9,447) 66.6 \%$ & $(10,495) 66.3 \%$ & $(19,942) 66.4 \%$ & \\
\hline Traditional dwelling/hut & $(2,20 I) 15.5 \%$ & $(2,526) 16.0 \%$ & $(4,727) \mid 5.8 \%$ & \\
\hline Flat or apartment & (I 170$) \mid .2 \%$ & (I7I) $1.1 \%$ & (34I) I.I\% & \\
\hline Cluster house in complex & (48) $0.3 \%$ & (47) $0.3 \%$ & (95) $0.3 \%$ & \\
\hline Townhouse (s-detached) & $0.2 \%$ & (4I) $0.3 \%$ & $0.2 \%$ & \\
\hline Semi-detached house & (121) $0.9 \%$ & (127) $0.8 \%$ & (248) $0.8 \%$ & \\
\hline House in backyard & (872) $6.2 \%$ & (97I) $6.1 \%$ & $(1,843) 6.1 \%$ & \\
\hline
\end{tabular}


Shack in backyard

Shack not in backyard

Flatlet on a larger property

Caravan/tent

Other

Source of drinking water

A municipality

Community water supply

A water vendor

Own service e.g. borehole

Flowing water/stream/

Do not know

Access to electricity

Meter or Other paying sources

Generator/solar/battery

Other

No access to electricity

Agricultural involvement

Yes

No

Main type of toilet facility used

Flush or chemical

Pit latrine or ecological

Bucket or other toilet

No toilet

Shared toilet facility

Yes

No

Do not know

Household member was a victim of any crime

Yes

No

Do not know

Rubbish removal

By local authority

Communal disposal

Own (no arrangement)

Source of energy for cooking

Electricity

Gas or Paraffin

Wood, coal or dung

Solar or other source

None

Residence

Urban areas

Rural areas

Province

Western cape

Eastern cape

Northern cape

Free state

Kwazulu-Natal

North west

Gauteng

Mpumalanga

Limpopo

http://aps.journals.ac.za
(523) $3.7 \%$

(6I7) $4.4 \%$

(36) $0.3 \%$

(3) $0.0 \%$

(I22) $0.9 \%$

$(10,5 \mid 4) 74.1 \%$

$(\mathrm{I}, 098) 7.7 \%$

(284) $2.0 \%$

(696) $4.9 \%$

$(\mathrm{I}, 498) 10.6 \%$

(90) $0.6 \%$

$(12,859) 90.6 \%$

(92) $0.6 \%$

(58) $0.4 \%$

$(\mathrm{I}, \mathrm{I} 73) 8.2 \%$

(4,5II) $31.8 \%$

$(9,67 I) 68.2 \%$

$(7,060) 49.7 \%$

$(6,173) 43.5 \%$

(486) $3.4 \%$

(463) $3.2 \%$

$(3,789) 26.7 \%$

$(9,898) 69.8 \%$

(19) $0.1 \%$

$(1,538) 10.8 \%$

$(12,608) 88.9 \%$

(30) $0.2 \%$

$(6,564) 46.2 \%$

(554) $3.9 \%$

$(6,919) 48.7 \%$

$(I 0,7 \mid 9) 75.5 \%$

(904) $6.37 \%$

$(2,447) 17.2 \%$

(34) $0.2 \%$

(I8) $0.1 \%$

$(7,005) 49.4 \%$

$(7, I 77) 50.6 \%$

(756) $5.3 \%$

$(2,766) 19.5 \%$

(429) $3.0 \%$

(928) $6.5 \%$

$(2,953) 20.8 \%$

$(\mathrm{I}, 336) 9.4 \%$

$(2,278) 16.1 \%$

$(\mathrm{I}, 167) 8.2 \%$

$(\mathrm{I}, 569) \mathrm{II} .1 \%$
(567) $3.6 \%$

(7I9) $4.5 \%$

(29) $0.2 \%$

(3) $0.0 \%$

(I43) $0.9 \%$

$(\mathrm{II}, 622) 73.4 \%$

$(\mathrm{I}, \mathrm{I} 63) 7.3 \%$

(353) $2.2 \%$

(83I) $5.3 \%$

$(\mathrm{I}, 765) 1 \mathrm{I} .1 \%$

(I06) $0.7 \%$

$(14,293) 90.2 \%$

(I33) $0.8 \%$

(65) $0.4 \%$

$(\mathrm{I}, 349) 8.5 \%$

$(5,376) 33.9 \%$

$(10,464) 66.1 \%$

$(7,953) 50.2 \%$

$(6,762) 42.6 \%$

(59I) $3.7 \%$

(534) $3.3 \%$

$(4,250) 26.8 \%$

(II,002) 69.5\%

(33) $0.2 \%$

$(\mathrm{I}, 864) \mathrm{I} I .8 \%$

$(13,931) 88.0 \%$

(39) $0.3 \%$

$(7,277) 45.9 \%$ (644) $4.1 \%$

$(7,746) 48.9 \%$

$(\mathrm{II}, 677) 73.7 \%$

$(\mathrm{I}, 123) 7.1 \%$

$(2,932) 18.5 \%$

(49) $0.3 \%$

(20) $0.1 \%$

$(7,77 I) 49.1 \%$

$(8,069) 50.9 \%$

(95I) $6.0 \%$

$(3,125) 19.7 \%$

(472) $3.0 \%$

$(\mathrm{I}, \mathrm{I} 20) 7.1 \%$

$(3,236) 20.4 \%$

(I,54I) $9.7 \%$

$(2,473) 15.6 \%$

$(\mathrm{I}, 309) 8.3 \%$

$(I, 6 I 3) 10.2 \%$
(I,090) 3.6\%

$(\mathrm{I}, 336) 4.5 \%$

(65) $0.2 \%$

(6) $0.0 \%$

(265) $0.9 \%$

$(22,136) 73.3 \%$

$x^{2}=10.4 ; p=0.1$

$(2,261) 7.5 \%$

(637) $2.1 \%$

$(1,527) 5.1 \%$

$(3,263) 10.9 \%$

(I96) $0.7 \%$

$(27,152) 90.4 \%$

$$
x^{2}=7.2 ; p=0.5
$$

(225) $0.7 \%$

(I23) $0.4 \%$

$(2,522) 8.4 \%$

$(9,887) 32.9 \%$

$(20,135) 67.1 \%$

(I5,0I3) $50.0 \%$

$(12,935) 43.0 \%$

(I,077) $3.5 \%$

(997) $3.3 \%$

$(8,039) 26.8 \%$

$(20,900) 69.6 \%$

(52) $0.2 \%$

$(3,402) । 1.3 \%$

$(26,539) 88.4 \%$

(69) $0.2 \%$

$(|3,84|) 46.1 \%$

$(1,198) 3.9 \%$

$(14,665) 48.8 \%$

$(22,396) 74.6 \%$

$(2,027) 6.7 \%$

$(5,379) \mid 7.9 \%$

(83) $0.2 \%$

(38) $0.1 \%$

$(14,776) 49.2 \%$

$(15,246) 50.8 \%$

$(I, 707) 5.7 \%$

$x^{2}=15.4 ; p=0.00$

$x^{2}=6.2 ; p=0.7$

$x^{2}=5.3 ; p=0.3$

$x^{2}=6.8 ; p=0.09$

$x^{2}=1.9 ; p=0.94$

$x^{2}=25.0 ; p=0.00$

$x^{2}=3.9 ; p=0.14$

$x^{2}=16.99 ; p=0.03$

$(5,891) 19.6 \%$

(90I) $3.0 \%$

$(2,048) 6.8 \%$

$(6,189) 20.6 \%$

$(2,877) 9.6 \%$

$(4,75 \mathrm{I}) \mid 5.8 \%$

$(2,476) 8.3 \%$

$(3,182) 10.6 \%$ 
In terms of the household's involvement in agricultural activities, considerably high proportions of mortality were noted in both sexes among households that were not involved in farming. Nevertheless, in comparison to females (31.8\%), males died more (33.9\%) in households that were involved in agriculture. An analysis by the source of household energy for cooking equally showed mortality differentials. More male deaths than female were reported among those who lived in households that used gas, paraffin, wood, coal or dung. Households that used electricity for cooking, however, reported less male deaths (73.7\%) than female deaths (75.5\%). Provincial differences revealed that Limpopo, Gauteng and KwaZulu-Natal accounted for fewer proportions of male deaths than female. Higher prevalence of male deaths than female deaths was observed in Western Cape, Free State, North West and Eastern Cape. On the other hand, there were no variations in mortality by sex in the Northern Cape and Mpumalanga.

Chi-square tests for independence, however, reported no statistical association between sex of the deceased and a number of factors. These include type of dwelling, source of drinking water for the household, access to electricity, rubbish disposal arrangements, type of toilet used by the household, whether the toilet was shared with other households, place of residence, and whether any of the household members had experienced any crime in the 12 months that preceded the survey date. These variables equally showed minimal or no difference in the prevalence of mortality when compared between the sexes. In this respect, the findings reveal that sex of the deceased did not have an association with most household economic and household environmental factors. Household demographics, on the other hand, was associated with sex of the deceased.

\section{Estimating the odds of male mortality}

Covariates that were deemed significant in the crosstabulations were used to examine the determinants of mortality among males. This multivariate analysis aimed to predict the probability of a death occurring in males and in females based on a binary logistic regression. With respect to table 2 , variables that determine the likelihood of mortality in males are age at death, race of the household head, sex of the household head, province where the household is located, source of energy for cooking and whether the household is involved in agriculture or not.

For the analysis of age at death, the age group 0I 4 was used as the reference age group. While age strongly predicts the likelihood of dying, the study found the odds of dying by age to be relatively small. Males in age groups 15-29 years and 45-59 years were 1.04 and 1.06 times more likely to die compared to females. Males in age groups 30-44 years, 60-74 years and $75+$ years were $0.94,0.91$ and 0.47 times less likely to die respectively - in turn favouring male survival. Thus, for ages above 74 years the likelihood of a male dying is about half of that of a female.

The probability of dying in males depended to a large extent on the race of the head of the household. Males were I.5 times more likely to die than females in households that were headed by a person of the White race compared to households headed than a Black person. The odds were relatively lower in Coloured and Indian-headed houses at 1.02 and 1.19 times respectively. While staying in a female-headed household was protective of female survival, it was also associated with the highest likelihood of dying among males (OR = 2.08).

In terms of the cooking energy source for the household, males were more likely to die than females in homes that used solar $(O R=1.15)$, gas/paraffin $(\mathrm{OR}=\mathrm{I.13})$ and wood or coal $(\mathrm{OR}=1.04)$. This is in comparison to households that used electricity for cooking. Additionally, households that never practiced agriculture were protective of male survival. Males from these households were 0.91 times less likely to die than females in comparison to households that never engaged in agriculture. Surprisingly, the analysis reveals higher survival among males than females in all the provinces when compared to those in the Western Cape. Statistically significant odds were reported in the Eastern Cape $(\mathrm{OR}=0.86), \quad$ KwaZulu-Natal $(O R=0.84) \quad$ and Limpopo $\quad(O R=0.83)$. 
Table 2: Results of a binary logistic regression showing the odds of male mortality across various household factors in South Africa between 2015 and 2016

\begin{tabular}{|c|c|c|c|}
\hline & $\begin{array}{c}\text { Adjusted odds } \\
\text { ratio }\end{array}$ & $95 \%$ Conf. Interval & $p$-value \\
\hline \multicolumn{4}{|l|}{ Age at death (in years) } \\
\hline $15-29$ & 1.04 & {$[0.936-|| 48]$.} & 0.492 \\
\hline $30-44$ & 0.94 & {$[0.860-1.027]$} & 0.171 \\
\hline $45-59$ & 1.06 & {$[0.966-1.154]$} & 0.232 \\
\hline $60-74$ & $0.9 I^{*}$ & {$[0.835-0.998]$} & 0.045 \\
\hline $75+$ & $0.47^{*}$ & {$[0.428-0.516]$} & 0.000 \\
\hline \multicolumn{4}{|l|}{$0-14[R C]$} \\
\hline \multicolumn{4}{|l|}{ Age of household head (in years) } \\
\hline $15-29$ & 0.97 & {$[0.4 \mid 5-2.282]$} & 0.949 \\
\hline $30-44$ & 1.18 & {$[0.505-2.772]$} & 0.699 \\
\hline $45-59$ & 1.37 & {$[0.584-3.205]$} & 0.470 \\
\hline $60-74$ & 1.57 & {$[0.670-3.678]$} & 0.299 \\
\hline $75+$ & 1.48 & {$[0.630-3.473]$} & 0.368 \\
\hline \multicolumn{4}{|l|}{$0-I 4[R C]$} \\
\hline \multicolumn{4}{|l|}{ Race of household head } \\
\hline Coloured & 1.02 & {$[0.9 \mid 1-1.153]$} & 0.685 \\
\hline Indian/Asian & 1.19 & {$[0.927-1.534]$} & 0.172 \\
\hline White & $1.50 *$ & {$[1.293-1.730]$} & 0.000 \\
\hline \multicolumn{4}{|l|}{ Black African [RC] } \\
\hline \multicolumn{4}{|l|}{ Sex of household head } \\
\hline Female & $2.08 *$ & {$[1.981-2.182]$} & 0.000 \\
\hline \multicolumn{4}{|l|}{ Male $[R C]$} \\
\hline \multicolumn{4}{|l|}{ Province } \\
\hline Eastern cape & $0.86^{*}$ & {$[0.758-0.984]$} & 0.028 \\
\hline Northern cape & 0.87 & {$[0.739-1.034]$} & 0.115 \\
\hline Free state & 0.99 & {$[0.850-\mathrm{I} .144]$} & 0.851 \\
\hline KwaZulu-Natal & $0.84 *$ & {$[0.738-0.961]$} & 0.011 \\
\hline North west & 0.94 & {$[0.812-1.077]$} & 0.352 \\
\hline Gauteng & 0.91 & {$[0.795-1.034]$} & 0.143 \\
\hline Mpumalanga & 0.89 & {$[0.773-1.034]$} & 0.132 \\
\hline Limpopo & $0.83^{*}$ & {$[0.721-0.959]$} & 0.011 \\
\hline \multicolumn{4}{|l|}{ Western Cape $[R C]$} \\
\hline \multicolumn{4}{|l|}{ Source of energy for cooking } \\
\hline Gas or Paraffin & $1.13 *$ & {$[1.025-1.239]$} & 0.014 \\
\hline Wood, coal or dung & 1.04 & {$[0.977-1.117]$} & 0.201 \\
\hline Solar or other source & 1.15 & {$[0.732-1.806]$} & 0.545 \\
\hline None & 1.06 & {$[0.549-2.043]$} & 0.864 \\
\hline \multicolumn{4}{|l|}{ Electricity $[\mathrm{RC}]$} \\
\hline \multicolumn{4}{|l|}{ Agricultural involvement } \\
\hline No & $0.91 *$ & {$[0.865-0.965]$} & 0.001 \\
\hline \multicolumn{4}{|l|}{ Yes $[R C]$} \\
\hline \multicolumn{4}{|l|}{$*=$ relationship was statistically significant at $\alpha<0.05$} \\
\hline $\begin{array}{l}\text { Discussion } \\
\text { Governments and stakeholders at both national and } \\
\text { global levels have acknowledged the reduction of }\end{array}$ & \multicolumn{3}{|c|}{$\begin{array}{l}\text { mortality as one of the most effective ways of } \\
\text { achieving the longevity dividend: a combined } \\
\text { economic, social and health benefits arising from } \\
\text { slowing the rate of ageing (Olshansky et al., 2007). }\end{array}$} \\
\hline http://aps.journals.ac.za & & & 4638 \\
\hline
\end{tabular}


Collective findings from the cross-tabulations and the inferential analysis indicate the following to be the strongest explanatory variables for male mortality in South Africa: ages of both the deceased and head of house, race of the household head, sex of the household head, region/province, source of energy for cooking and involvement in agriculture.

The results further show that male mortality increases with age up until the age group 45-59 years. The drop could suggest a reduction in risky activities among older Males. Behaviours like high alcohol use and reckless driving have been noted to be lower among older males than younger ones (Resnick, 2004). Comparatively lower adult mortality among males could also emanate from increasing levels of female mortality in older ages. More female deaths than male among older populations have been attributed to the fact that older females are more likely to live a sedentary life with a poor self-rated health attitude compared to their male counterparts (Carmel et al., 2007).

This analysis also shows that population group or race of the head of household is one of the major factors influencing male mortality in South Africa. The finding that a White head of house is strongly associated with both higher male mortality and female survival should, however, be interpreted with caution. This is mainly because most literature put Whites at a higher survival advantage than other races. However, this study cannot precisely deduce the race of the deceased, as the data that was analysed only collected racial information for the head of the household. This is from an assumption that a household member could be of a race that is different from the head of the house. Nevertheless, other studies have reported a "White" mortality disadvantage among rural White-headed households, and those with comparable socio-economic status and healthcare access to Blacks (James and Cossman, 2017; Krueger et al., 20II).

Sex of the household head was equally a predictor of the male mortality in the household. One would ascribe the higher male mortality among female headed households in South Africa to low socioeconomic status among most females, which makes their households more susceptible to mortality risk factors. However, this raises several key areas for further research. For instance, what characteristics do female heads of households have that hinder male survival while favouring female survival? Why are these factors the way they are? What would be the necessary reforms needed to address these factors?

Surprisingly, regional comparisons indicate less probabilities of male mortality in all the other provinces when compared to Western Cape, which in all logic should imply an overall lower male mortality. However, the given high male mortality locale of the study, and the fact that only household factors were considered in the analysis goes to suggest the critical influence of other factors towards mortality outcomes. Such factors could constitute personal behaviours, health status and physiological status.

\section{Conclusion}

The findings from this study yield policy and programme-level implications that can be pertinent for South Africa, and other African countries with similar socio-economic context. Multiple development sectors in the country need to put concerted efforts towards mitigating the mortality burden by employing age-specific interventions. These could include efforts for further investment in maternal mortality interventions, immunisation, child protection programmes, youth skills development for the particular demographic, and access to quality and affordable healthcare. Further analysis, however needs to look into the relationship between race and male mortality, particularly among White household heads. The overall low male mortality calls for the need to understand the life experiences of males in age groups $30-44,60-74$ and $75+$, as they exhibit higher survival. Learning this will enable create favourable conditions for males with lower high mortality experiences. Similar lessons need to be drawn from younger heads of households, as their characteristics depict favourable conditions for male survival.

Raising the socio-economic status of females goes a long way at averting premature male mortality. Females, as primary caregivers, have a vital role of ensuring safety from mortality hazards among household members. Thus, improving their levels of literacy through investments in both formal and informal education can ensure that females are aware of protective factors of mortality. Proper education also increases their likelihood of economic independence, which at household level, is associated with longevity. While this is the case, households that experience deaths of male heads are more likely to expose members to increased socio-economic risk in the resulting female-headed household (Hunter et al., 2007). Thus, in a way, ensuring survival of male household heads can be implied to be protective of male mortality through this cyclic relationship.

With this logic in mind plus the understanding that household decision-making is largely maledominated, there is need to ensure male inclusiveness in advocacy interventions. Male partner understanding, for instance, on the need to use contraception in order to avoid closely spaced births would be critical to ensuring reduced mortality. 


\section{References}

Alwan, A., 201I. Global status report on noncommunicable diseases 2010. World Health Organization.

Babb, C., Urban, M., Kielkowski, D., Kellett, P., 2014. Prostate cancer in South Africa: pathology based national cancer registry data (1986-2006) and mortality rates (1997-2009). Prostate Cancer 2014.

Beltrán-Sánchez, H., Finch, C.E., Crimmins, E.M., 2015. Twentieth century surge of excess adult male mortality. Proc. Natl. Acad. Sci. I I 2, 89938998.

Bor, J., Herbst, A.J., Newell, M.-L., Bärnighausen, T., 2013. Increases in adult life expectancy in rural South Africa: valuing the scale-up of HIV treatment. Science

339 ,

10.1 |26/science. 12304 |3. https://doi.org//0.1 | 26/science.12304/3

Carmel, S., Baron-Epel, O., Shemy, G., 2007. The will-to-live and survival at old age: Gender differences. Soc. Sci. Med. 65, 5I 8-523.

Cervellati, M., Sunde, U., 2005. Human capital formation, life expectancy, and the process of development. Am. Econ. Rev. 95, 1653-1672.

Chisumpa, V.H., Odimegwu, C.O., De Wet, N., 2017. Adult mortality in sub-saharan Africa, Zambia: Where do adults die? SSM - Popul. Health 3 ,

227-235. https://doi.org/I0.1016/j.ssmph.2017.02.00 I

Clark, S.J., Collinson, M.A., Kahn, K., Drullinger, K., Tollman, S.M., 2007. Returning home to die: circular labour migration and mortality in South Africa I. Scand. J. Public Health 35, 35-44.

Cornell, M., Johnson, L.F., Wood, R., Tanser, F., Fox, M.P., Prozesky, H., Schomaker, M., Egger, M., Davies, M.-A., Boulle, A., for the International Epidemiology Databases to Evaluate AIDSSouthern Africa collaboration, 2017. Twelve-year mortality in adults initiating antiretroviral therapy in South Africa. J. Int. AIDS Soc. 20, 21902. https://doi.org/I0.7448/IAS.20.I.21902

Cornell, M., Schomaker, M., Garone, D.B., Giddy, J., Hoffmann, C.J., Lessells, R., Maskew, M., Prozesky, H., Wood, R., Johnson, L.F., 2012. Gender differences in survival among adult patients starting antiretroviral therapy in South Africa: a multicentre cohort study. PLoS Med. 9, el00I304.

De Wet, N., 2016. Gendered differences in AIDS and AIDS-related cause of death among youth with secondary education in South Africa, 2009-20II. SAHARA-J J. Soc. Asp. HIVAIDS 13, I70-177. https://doi.org// 0.1080/I 7290376.20I6.1 242434

Dong, H., Manfredini, M., Kurosu, S., Yang, W., Lee, J.Z., 2017. Kin and birth order effects on male child mortality: three East Asian populations, 1716-1945. Evol. Hum. Behav. 38, 208-216.

Folb, N., Timmerman, V., Levitt, N.S., Steyn, K., Bachmann, M.O., Lund, C., Bateman, E.D., Lombard, C., Gaziano, T.A., Zwarenstein, M., 2015. Multimorbidity, control and treatment of non-communicable diseases among primary healthcare attenders in the Western Cape, South Africa. SAMJ South Afr. Med. J. 105, 642-647.

Heaton, T.B., Amoateng, A.Y., 2007. The family context for racial differences in child mortality in South Africa. Fam. Househ. Post-Apartheid South Afr. Socio-Demogr. Perspect.

Howlader, M.R., 2013. An analyzing the sociodemographic variables impact on health status of Bangladesh.

Hunter, L.M., Twine, W., Patterson, L., 2007. “'Locusts are now our beef": Adult mortality and household dietary use of local environmental resources in rural South Africal. Scand. J. Public Health 35, 165-174. https://doi.org//0.1080/I403495070I 356385

International Longevity Centre, 2012. Global Perspectives on Multigenerational Households and Intergenerational Relations.

Jadhav, A., Weitzman, A., Smith-Greenaway, E., 2016. Household sanitation facilities and women's risk of non-partner sexual violence in India. BMC Public Health 16, II 39.

James, W., Cossman, J.S., 2017. Long-Term Trends in Black and White Mortality in the Rural United States: Evidence of a Race-Specific Rural Mortality Penalty. J. Rural Health 33, 2 I-3I.

Johnson, L.F., May, M.T., Dorrington, R.E., Cornell, M., Boulle, A., Egger, M., Davies, M.-A., 2017. Estimating the impact of antiretroviral treatment on adult mortality trends in South Africa: A mathematical modelling study. PLoS Med. I4, el002468.

Kahn, K., Garenne, M.L., Collinson, M.A., Tollman, S.M., 2007. Mortality trends in a new South Africa: hard to make a Fresh start I. Scand. J. Public Health 35, 26-34.

Krueger, P.M., Saint Onge, J.M., Chang, V.W., $201 \mathrm{I}$. Race/Ethnic Differences in Adult Mortality: The Role of Perceived Stress and Health Behaviors*. Soc. Sci. Med. 1982 73, 10.1016/j.socscimed.20II.08.007. https://doi.org/I0.10 I6/j.socscimed.20I I.08.007

Krueger, P.M., Tran, M.K., Hummer, R.A., Chang, V.W., 20I5. Mortality Attributable to Low Levels of Education in the United States. PLOS ONE I0, e013/809.

https://doi.org//0.1371/journal.pone.0131809

Mmusi-Phetoe, R.M., 2016. Social factors determining maternal and neonatal mortality in 
South Africa: A qualitative study. Curationis 39, I8.

Nathan, H.S.K., 20I2. Gender-based indicators in human development: Correcting for missing women.

National Planning Commission, 201I. National development plan for vision 2030. Pretoria South Afr.

Nojilana, B., Bradshaw, D., Pillay-van Wyk, V., Msemburi, W., Laubscher, R., Somdyala, N.I., Joubert, J.D., Groenewald, P., Dorrington, R.E., 2016a. Emerging trends in non-communicable disease mortality in South Africa, 1997-2010. SAMJ South Afr. Med. J. 106, 477-484.

Nojilana, B., Bradshaw, D., Pillay-van Wyk, V., Msemburi, W., Somdyala, N., Joubert, J.D., Groenewald, P., Laubscher, R., Dorrington, R.E., 2016b. Persistent burden from noncommunicable diseases in South Africa needs strong action. SAMJ South Afr. Med. J. 106, 436437.

Olshansky, S., Perry, D., Miller, R.A., Butler, R.N., 2007. Pursuing the longevity dividend. Ann. N. Y. Acad. Sci. II |4, I I-13.

Olufunke, F., \& Obafemi, O. (20II). Ethnicity and child survival in Nigeria. African Population Studies, 25(I). https://doi.org/10.I I564/25-I-258

Pillay-van Wyk, V., Msemburi, W., Laubscher, R., Dorrington, R.E., Groenewald, P., Glass, T., Nojilana, B., Joubert, J.D., Matzopoulos, R., Prinsloo, M., 2016. Mortality trends and differentials in South Africa from 1997 to 2012: second National Burden of Disease Study. Lancet Glob. Health 4, e642-e653.

Pongou, R., 2013. Why is infant mortality higher in boys than in girls? A new hypothesis based on preconception environment and evidence from a large sample of twins. Demography 50, 42I-444.

Resnick, B., 2004. Risky Behaviors in Older Adults [WWW Document]. Medscape. URL http://www.medscape.org/viewarticle/464727 (accessed 2.20.19).

Rogers, R.G., Hummer, R.A., Krueger, P.M., 2005. Adult Mortality - Chapter 10, in: Handbook of Population. Springer Publishers, NY, pp. 283-309.

Sartorius, B.K., Sartorius, K., Chirwa, T.F., Fonn, S., 20I I. Infant mortality in South Africa-distribution, associations and policy implications, 2007: an ecological spatial analysis. Int. J. Health Geogr. I0, 61.
Sherriff, B., MacKenzie, S., Swart, L.-A., Seedat, M.A., Bangdiwala, S.I., Ngude, R., 2015. A comparison of urban-rural injury mortality rates across two South African provinces, 2007. Int. J. Inj. Contr. Saf. Promot. 22, 75-85.

Shoko, M. (20II). Is there a mortality differential by marital status among women in South Africa? A study on a rural sub-district of Mpumalanga Province in the North-East South Africa. African Population Studies, 25(I). https://doi.org/I0.I I564/25-I-263.

Singh, E., Joffe, M., Cubasch, H., Ruff, P., Norris, S., Pisa, P., 2016. Breast cancer trends differ by ethnicity: a report from the South African National Cancer Registry (1994-2009). Eur. J. Public Health 27, I73-I78.

Statistics South Africa, 2018. Mortality and Causes of Death in South Africa: 2016 Findings from Death Notification. Statistics South Africa.

Statistics South Africa, 2017. Mid-year population estimates, 2017. Pretoria South Afr. Stats SA.

Statistics South Africa, 2016a. Community Survey 2016 (Statistical release No. P030I). Statistics South Africa, Pretoria.

Statistics South Africa, 2016b. Community Survey 2016 Technical Report (Statistical release No. P030I). Statistics South Africa, Pretoria.

Statistics South Africa, 2014. Mid-year population estimates, 2014. Pretoria South Afr. Stats SA.

Statistics South Africa, 2008. Mortality and causes of death in South Africa: Findings from death notification, 2006 (Statistical release No. P0309.3). Statistics South Africa, Pretoria.

Tomlinson, R., 2017. Urbanization in post-apartheid South Africa. Routledge.

Udjo, E. O., \& Lalthapersad-Pillay, P. (20/4). Mortality from non-communicable diseases in South Africa, 1997-2009. African Population Studies, 28(0), 60I-609. https://doi.org/I0.II 564/28-0-5 I8

Wira, C.R., Fahey, J.V., 2008. A new strategy to understand how HIV infects women: identification of a window of vulnerability during the menstrual cycle. AIDS Lond. Engl. 22, 1909-1917. https://doi.org/I0.1097/QAD.0b0 I 3e3283060ea4

Zere, E., McIntyre, D., 2003. Inequities in under-five child malnutrition in South Africa. Int. J. Equity Health 2, 7. https://doi.org//0.II86/I475-9276-27 